\title{
Impact of Prosthesis-Patient Mismatch on 1-Year Outcomes after Transcatheter Aortic Valve Implantation: Meta-analysis of 71,106 Patients
}

Michel Pompeu Barros Oliveira Sá1-3, MD, MSc, PhD; Luiz Rafael Pereira Cavalcanti ${ }^{1,2}$, MD; Felipe Augusto Santos Sarargiotto 1,2, MD; Álvaro Monteiro Perazzo 1,2, MD; Sérgio da Costa Rayol 1,2, MD; Roberto Gouveia Silva Diniz ${ }^{1,2}$, MD; Frederico Browne Correia Araújo Sá ${ }^{1,2}$, MD; Alexandre Motta Menezes ${ }^{1,2}$, MD; Ricardo Carvalho Lima ${ }^{1-3}$, MD, $^{2}$ MSc, PhD, ChM, AATS

Key question

What are the incidence and impact of prosthesispatient mismatch (PPM) on the outcomes of TAVI?

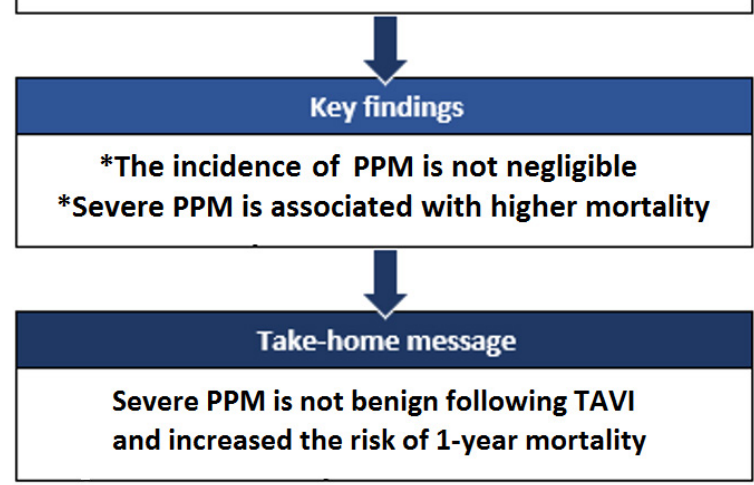

\section{Odds ratio and $95 \% \mathrm{Cl}$} 1-year Mortality

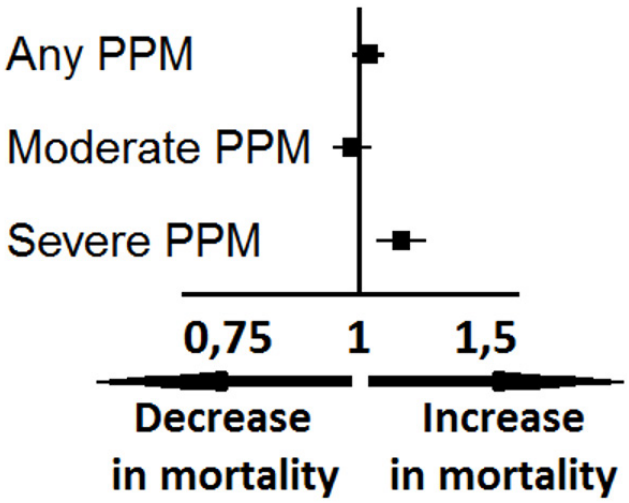

\section{Abstract}

Objectives: This study sought to evaluate the impact of prosthesis-patient mismatch (PPM) on the risk of early-term mortality after transcatheter aortic valve implantation (TAVI).

Methods: Databases (Medical Literature Analysis and Retrieval System Online [MEDLINE], Excerpta Medica dataBASE [EMBASE], Cochrane Controlled Trials Register [CENTRAL/CCTR], ClinicalTrials. gov, Scientific Electronic Library Online [SciELO], Latin American and Caribbean Literature on Health Sciences [LILACS], and Google Scholar) were searched for studies published until February 2019. PPM after TAVI was defined as moderate if the indexed effective orifice area (iEOA) was between $0.85 \mathrm{~cm}^{2} / \mathrm{m}^{2}$ and $0.65 \mathrm{~cm}^{2} / \mathrm{m}^{2}$ and as severe if $\mathrm{iEOA} \leq 0.65 \mathrm{~cm}^{2} / \mathrm{m}^{2}$.

Results: The search yielded 1,092 studies for inclusion. Of these, 18 articles were analyzed, and their data extracted. The total number of patients included who underwent TAVI was

'Division of Cardiovascular Surgery of Pronto-Socorro Cardiológico Universitário de Pernambuco (PROCAPE), Recife, PE, Brazil.

¿Universidade de Pernambuco (UPE), Recife, PE, Brazil.

${ }^{3}$ Nucleus of Postgraduate Studies and Research in Health Sciences at Faculdade de Ciências Médicas and Instituto de Ciências Biológicas (FCM/ICB), Recife, PE, Brazil.
71,106. The incidence of PPM after TAVI was $36.3 \%$ (25,846 with PPM and 45,260 without PPM). One-year mortality was not increased in patients with any PPM (odds ratio [OR] $1.021,95 \%$ confidence interval $[\mathrm{Cl}]$ 0.979-1.065, $P=0.338$ ) neither in those with moderate PPM (OR 0.980, 95\% Cl 0.933-1.029, $P=0.423$ ). Severe PPM was separately associated with high risk (OR $1.109,95 \% \mathrm{Cl}$ 1.041-1.181, $P=0.001$ ).

Conclusion: The presence of severe PPM after TAVI increased early-term mortality. Although moderate PPM seemed harmless, the findings of this study cannot not rule out the possibility of it being detrimental, since there are other registries that did not address this issue yet.

Keywords: Aortic Stenosis. Transcatheter Aortic Valve Replacement. Heart Valve Prosthesis. Meta-Analysis. ProsthesisPatient Mismatch.

Correspondence Address:

Michel Pompeu Barros Oliveira Sá

(iD) https://orcid.org/0000-0001-5356-2996

Pronto-Socorro Cardiológico de Pernambuco (PROCAPE)

Rua dos Palmares, S/N - Santo Amaro - Recife, PE, Brazil - Zip code: 74970-240 E-mail: michel_pompeu@yahoo.com.br

Article received on February 24th 2019. Article accepted on April 27th, 2019. 


\begin{tabular}{|c|c|c|c|}
\hline \multicolumn{4}{|c|}{ Abbreviations, acronyms \& symbols } \\
\hline ARE & $=$ Aortic root enlargement & MEDLINE & $=$ Medical Literature Analysis and Retrieval System \\
\hline AVR & $=$ Aortic valve replacement & & Online \\
\hline BSA & $=$ Body surface area & OR & = Odds ratio \\
\hline CENTRAL/CCTR & $=$ Cochrane Controlled Trials Register & PICO & = Patient, intervention, comparison, outcome \\
\hline $\mathrm{Cl}$ & $=$ Confidence interval & PPM & $=$ Prosthesis-patient mismatch \\
\hline EMBASE & $=$ Excerpta Medica dataBASE & PRISMA & $=$ Preferred Reporting Items for Systematic Reviews \\
\hline EOA & = Effective orifice area & & and Meta-Analyses \\
\hline iEOA & $=$ Indexed effective orifice area & SAVR & $=$ Surgical aortic valve replacement \\
\hline LILACS & $\begin{aligned}= & \text { Latin American and Caribbean Literature on } \\
& \text { Health Sciences }\end{aligned}$ & $\begin{array}{l}\text { SciELO } \\
\text { TAVI }\end{array}$ & $\begin{array}{l}=\text { Scientific Electronic Library Online } \\
=\text { Transcatheter aortic valve implantation }\end{array}$ \\
\hline
\end{tabular}

\section{INTRODUCTION}

\section{Rationale}

The idea of prosthesis-patient mismatch (PPM), firstly proposed by Rahimtoola et al. ${ }^{[1]}$ and reintroduced by Pibarot et al. ${ }^{[2]}$, provided the logical framework to select the proper prosthesis with the data of the indexed effective orifice area (iEOA), derived from the effective orifice area (EOA) of the prosthesis and the patient's body surface area (BSA). Pibarot et al. ${ }^{[3]}$ has proposed avoiding an iEOA lower than $0.85 \mathrm{~cm}^{2} / \mathrm{m}^{2}$ to prevent PPM, since the consequence of using prostheses with a small EOA relative to the BSA would be the obstruction of the outflow of the left ventricle, which would not favour the reverse remodeling of the hypertrophied left ventricle.

Our group published recently a meta-analysis ${ }^{[4]}$ in order to evaluate the impact of PPM on the risk of perioperative, early-, mid-, and long-term mortality rates after surgical aortic valve replacement (SAVR), showing increases in mortality of $49 \%, 46 \%$, $36 \%$, and $53 \%$, respectively.

This time, we aimed to address the same issue in the scenario of PPM after transcatheter aortic valve implantation (TAVI).

\section{Objectives}

We aimed to investigate whether PPM increases the risk for death after TAVI. This analysis was planned in accordance with current guidelines for performing comprehensive systematic reviews and meta-analysis, including the Preferred Reporting Items for Systematic Reviews and Meta-Analyses (PRISMA) ${ }^{[5]}$ guidelines.

\section{METHODS}

\section{Eligibility Criteria}

With the patient, intervention, comparison, outcome (PICO) strategy, studies were considered if: 1) the population comprised patients who underwent TAVl; 2) there was a group of patients who developed moderate PPM (with iEOA between $0.85 \mathrm{~cm}^{2} / \mathrm{m}^{2}$ and $0.65 \mathrm{~cm}^{2} / \mathrm{m}^{2}$ ) or severe PPM (iEOA $\leq 0.65 \mathrm{~cm}^{2} / \mathrm{m}^{2}$ ) after TAVI; $3)$ there was a control group of patients with non-significant/ no PPM (iEOA > $0.85 \mathrm{~cm}^{2} / \mathrm{m}^{2}$ ); 4) outcomes included 1-year mortality rates; and 5) studies were retrospective, prospective, randomized, or non-randomized.

\section{Information Sources}

The following databases were used (until February 2019): Medical Literature Analysis and Retrieval System Online (MEDLINE), Excerpta Medica dataBASE (EMBASE), Cochrane Controlled Trials Register (CENTRAL/CCTR), ClinicalTrials.gov, Scientific Electronic Library Online (SciELO), Latin American and Caribbean Literature on Health Sciences (LILACS), Google Scholar, and reference lists of relevant articles.

\section{Search}

We conducted the search with the following terms: "mismatch OR PPM OR patient-prosthesis mismatch OR prosthesis-patient mismatch" AND "AVR OR aortic valve replacement" AND "percutaneous OR transcatheter OR transluminal OR transarterial OR transapical OR transaortic OR transcarotid OR transsubclavian OR transaxillary OR transiliac OR transfemoral".

\section{Study Selection}

The following steps were taken: 1) identification of titles of records through databases searching; 2 ) removal of duplicates; 3 ) screening and selection of abstracts; 4) assessment for eligibility through full-text articles; and 5) final inclusion in study. One reviewer followed steps 1 to 3. Two independent reviewers followed the step 4 and selected the studies. Inclusion or exclusion of studies was decided unanimously. When there was disagreement, a third reviewer made the final decision.

\section{Data Items}

The crude end points were 1-year mortality rates.

\section{Data Collection Process}

Two independent reviewers extracted the data. When there was disagreement about the data, a third reviewer checked them and made the final decision. From each study, we extracted patient's characteristics, study design, and outcomes. When the 
data were not clearly available in the articles, we contacted the authors of the original articles by e-mail.

\section{Summary Measures}

The principal summary measures were odds ratio (OR) with 95\% confidence interval (Cl) and P-values (considered statistically significant when $P<0.05)$ for death. The meta-analysis was completed with the software Comprehensive Meta-Analysis (version 2, Biostat, Inc., Englewood, New Jersey).

\section{Synthesis of Results}

Forest plots were generated for graphical presentations of clinical outcomes, and we performed the $\mathrm{I}^{2}$ test and $\mathrm{X}^{2}$ test for the assessment of heterogeneity across the studies ${ }^{[3]}$. Inter-study heterogeneity was explored using the $x^{2}$ statistic, but the $\mathrm{I}^{2}$-value was calculated to quantify the degree of heterogeneity across the studies that could not be attributable to chance alone. When $I^{2}$ was more than $50 \%$, significant statistical heterogeneity was considered to be present. Each study was summarized by the OR, whose values were combined across studies using a weighted DerSimonian-Laird random effects mode $\left.\right|^{[7]}$.

\section{Risk of Bias Across Studies}

To assess publication bias, a funnel plot was generated for each outcome, statistically assessed by Begg and Mazumdar's test $^{[8]}$ and Egger's test ${ }^{[9]}$.

\section{Sensitivity Analysis}

We analyzed the pool data regarding the outcomes according to PPM severity (moderate or severe). We also investigated the influence of each study on the overall effect - by sequentially removing one study - in order to test the robustness of the main results, so that we could verify whether any study had an excessive influence on the overall results.

\section{RESULTS}

\section{Study Selection}

A total of 1,092 citations were identified, of which 116 studies were potentially relevant and retrieved as full-text. Seventeen publications ${ }^{[10-26]}$ fulfilled our eligibility criteria. Interobserver reliability of study relevance was excellent (Kappa $=0.85$ ). Agreement for decisions related to study validity was very good (Kappa=0.86). The search strategy can be seen in Figure 1.

\section{Study Characteristics}

A total of 71,106 patients (moderate/severe PPM: 25,466 patients; non-significant/no PPM: 45,260 patients) were included from studies published from 2011 to 2019. The incidence of moderate/severe PPM after TAVI was 36.3\% (moderate PPM: 24.5\%; severe PPM: 11.8\%). There were studies mostly from North America and Europe; none from Latin America. Most of the studies were observational $(n=15,83.3 \%)$, but all of the observational studies had some multivariate adjustment for possible confounders. All of the studies measured iEOA directly in each patient by Doppler echocardiography following TAVI. One-year mortality ranged in the studies from $1.9 \%$ to $19.5 \%$.

\section{Synthesis of Results (Looking into Moderate and Severe PPM as a Whole)}

The OR for 1-year mortality in the "any PPM" group compared with the "non-significant/no PPM" group in each study is reported in Figure 2. There was evidence of low heterogeneity of treatment effect among the studies for 1-year mortality. The overall OR $(95 \% \mathrm{Cl})$ of 1-year mortality showed no statistically significant difference between the groups (random effect model: OR 1.021, 95\% Cl 0.979-1.065, $P=0.338$ ).

\section{Sensitivity Analysis (Looking into Moderate and Severe PPM Separately)}

The OR for 1-year mortality in the "moderate PPM" group compared with the "non-significant/no PPM" group in each study is reported in Figure 3. There was evidence of low statistical heterogeneity of treatment effect among the studies for 1-year mortality. The overall OR ( $95 \%$ Cl) of 1-year mortality showed no statistically significant difference between the groups (random effect model: OR 0.980, 95\% Cl 0.933-1.029, $P=0.423$ ).

The OR for 1-year mortality in the "severe PPM" group compared with the "non-significant/no PPM" group in each study is reported in Figure 4. There was evidence of high statistical heterogeneity of treatment effect among the studies for perioperative mortality. The overall OR (95\% Cl) of 1-year mortality showed a statistically significant difference between the groups, with higher risk in the "severe PPM" group (random effect model: OR 1.109, 95\% Cl 1.041-1.181, $P=0.001$ ) than in the "non-significant/no PPM" group.

Sensitivity analyses performed by removing each single study from the meta-analysis to determine the influence of individual data sets to the pooled ORs showed that none of the studies had a particular impact on the results.

\section{Risk of Bias Across Studies}

Funnel plot analysis (Figure 5) disclosed no asymmetry around the axis for the outcomes, which means that we have low risk of publication bias related to these.

\section{DISCUSSION}

\section{Summary of Evidence}

To our knowledge, this is the largest meta-analysis of studies performed to date that provides additional value by demonstrating that patients with severe PPM have higher risk for 1-year mortality than those with non-significant/no PPM. We also observed that more than one third of the patients leave the operation room with significant PPM, having this aspect a negative impact. Moreover, mortality rates increased only with severe PPM, being moderate PPM not as harmful as severe PPM in terms of mortality rates. 


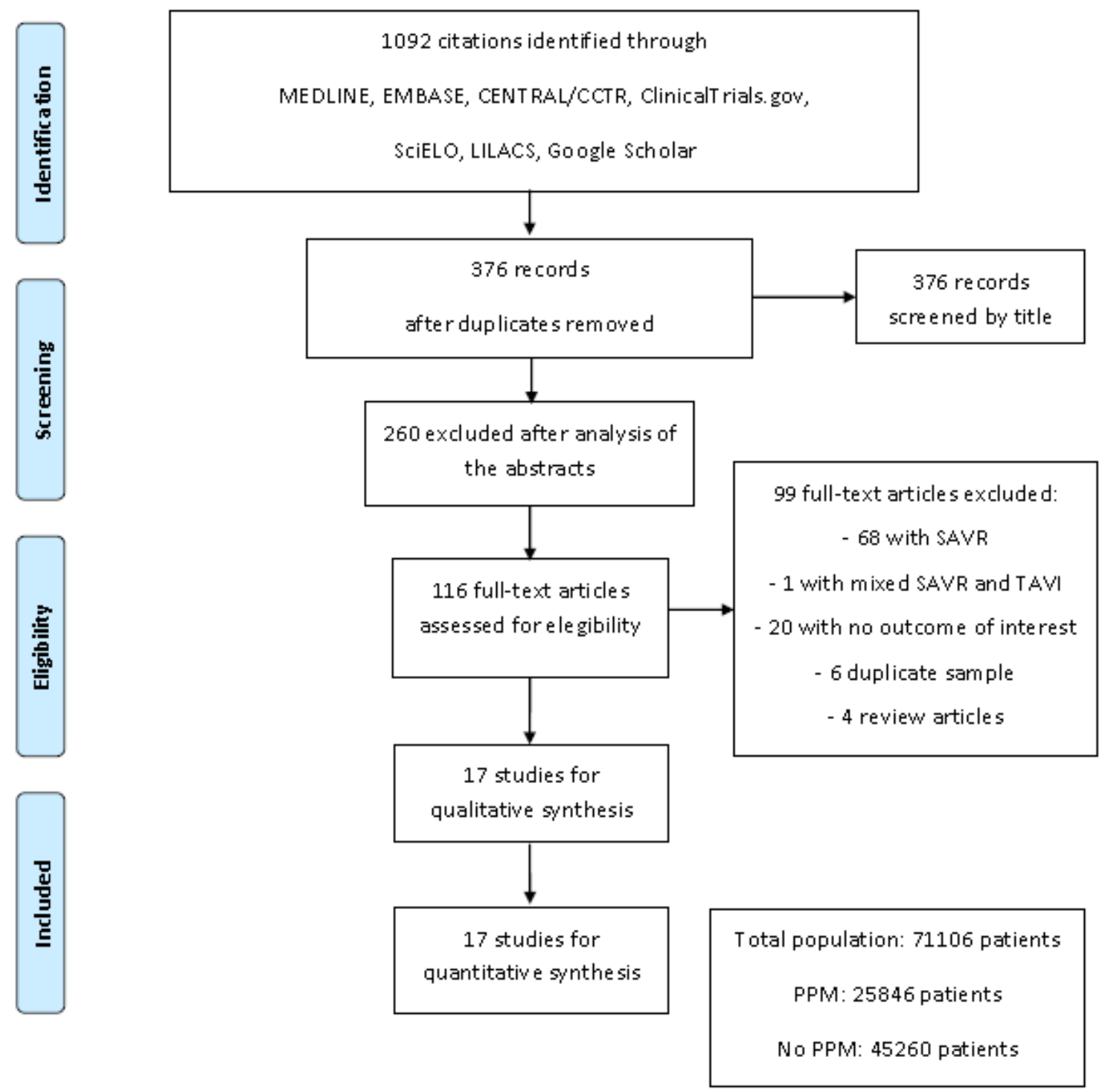

Fig. 1 - Flow diagram of studies included in data search.

CENTRAL/CCTR=Cochrane Controlled Trials Register; EMBASE=Excerpta Medica dataBASE; LILACS=Latin American and Caribbean Literature on Health Sciences; MEDLINE=Medical Literature Analysis and Retrieval System Online; PPM=prosthesis-patient mismatch; SAVR=surgical aortic valve replacement; SCiELO=Scientific Electronic Library Online; TAVI=transcatheter aortic valve implantation

\section{PPM after TAVI - a Playground (for Problems) that Must Not Be Neglected and Should Be Avoided}

These results have important clinical implications given that PPM is a potentially modifiable risk factor. Dayan et al. ${ }^{[27]}$ explains the association of PPM and increase of mortality by the fact that the left ventricle function would be highly vulnerable to any residual afterload, which sometimes means poor regression of the left ventricle hypertrophy and poor improvement of symptoms.

The first step to avoid PPM after TAVI would be to predict the risk of PPM before the procedure. This can be achieved by calculating the predicted iEOA using the normal EOA for the anticipated model of transcatheter valve and the patient's aortic annulus size, as suggested by Hahn et al. ${ }^{[28]}$ As suggested by Pibarot and Clavel[ ${ }^{[3]}$, if a risk of severe PPM is anticipated on the basis of the predicted iEOA, several strategies may be considered to prevent PPM, including: 1) overexpansion of the initially selected transcatheter valve; 2 ) selecting another type of transcatheter valve with larger EOA; or 3) fracturing the stent of the failed bioprosthesis in case of valve-in-valve procedure.

Surgeons must weigh up risks and benefits of these strategies, which is not yet well established and will have to be validated in future studies. Importantly, the prevention of PPM should not be achieved at the cost of more paravalvular regurgitation or lesser valve durability. For a given degree of severity, paravalvular 
Study name

León del Pino 2019
Lavagna 2019
VIVID Registry 2018
STS/ACC TVT Registry 2018
Seoudy 2018
Schofer 2018
OCEAN-TAVI Registry 2018
Zbroñski 2017
PARTNER II Nested Registry 2017
CoreValve US High Risk Pivotal Trial 2016
Poulin 2016
NOTION Trial 2016
PARTNER I Trial 2014
PARTNER I NRCA Registry 2014
Muñoz-García 2013
Kukucka 2013
Van Linden 2013
Ewe 2011
Overall effect

Statistics for each study

$\begin{array}{cccc}\begin{array}{c}\text { Odds } \\ \text { ratio }\end{array} & \begin{array}{c}\text { Lower } \\ \text { limit }\end{array} & \begin{array}{c}\text { Upper } \\ \text { limit }\end{array} & \text { p-Value } \\ 2,063 & 0,639 & 6,659 & 0,226 \\ 0,930 & 0,263 & 3,282 & 0,910 \\ 0,790 & 0,505 & 1,236 & 0,302 \\ 1,017 & 0,973 & 1,063 & 0,461 \\ 1,017 & 0,639 & 1,619 & 0,942 \\ 1,149 & 0,867 & 1,524 & 0,334 \\ 1,272 & 0,721 & 2,243 & 0,406 \\ 1,135 & 0,448 & 2,875 & 0,789 \\ 0,634 & 0,356 & 1,129 & 0,122 \\ 1,818 & 0,587 & 5,629 & 0,300 \\ 1,500 & 0,091 & 24,680 & 0,777 \\ 0,829 & 0,041 & 16,747 & 0,902 \\ 0,808 & 0,451 & 1,446 & 0,473 \\ 1,045 & 0,795 & 1,372 & 0,753 \\ 3,123 & 1,033 & 9,437 & 0,044 \\ 1,508 & 0,796 & 2,856 & 0,207 \\ 1,273 & 0,485 & 3,342 & 0,624 \\ 0,177 & 0,010 & 3,096 & 0,236 \\ 1,021 & 0,979 & 1,065 & 0,338\end{array}$

Test for heterogeneity: $\mathrm{Chi}^{2}=15.35 ; \mathrm{df}=17(\mathrm{P}=0.570) ; \mathrm{I}^{2}=0.0 \%$

Test for overall random effect: $Z=0.96(P=0.338)$

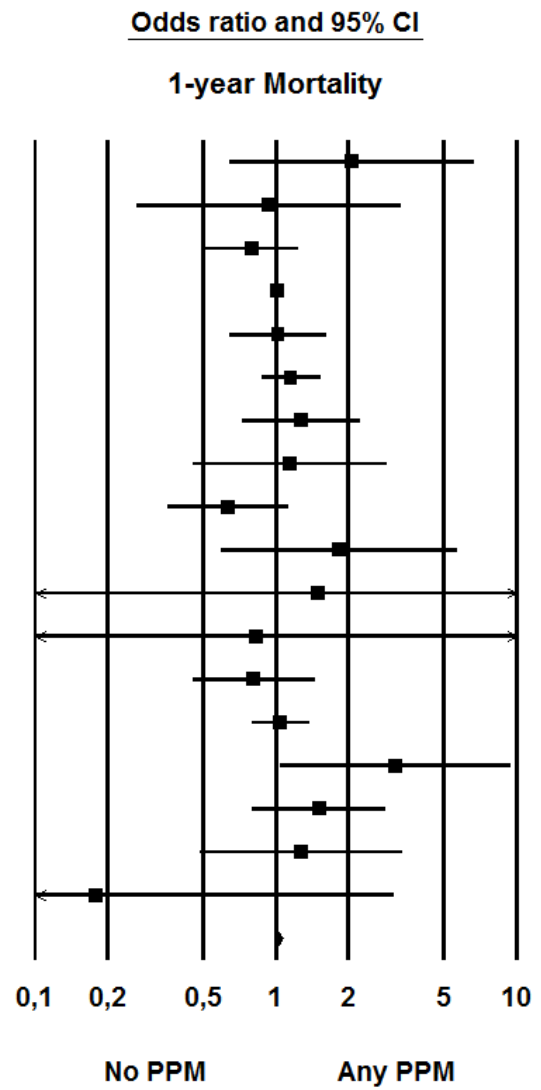

Fig. 2 - Odds ratio and conclusions plot of 1-year mortality for any prosthesis-patient mismatch (PPM). This figure shows the summary effect of no/any PPM on 1-year mortality.

$\mathrm{Cl}=$ confidence interval

regurgitation indeed has a greater impact than PPM on clinical outcomes. Pibarot and Clavel[ ${ }^{[3]}$ suggest that this might be explained by the fact that patients undergoing TAVI generally have severe aortic stenosis and their left ventricle is, therefore, adapted to pressure overload, but not to volume overload.

\section{SAVR with Aortic Root Enlargement (ARE) as an Option to Avoid Predicted PPM after TAVI}

Haunschild et al. ${ }^{[29]}$ performed a single-centre, retrospective, propensity-matched analysis of 4,120 patients receiving isolated aortic valve replacement (AVR), of whom 171 (4\%) had concomitant ARE, between January 2005 and December 2015, in order to avoid PPM. Early mortality was not statistically significantly different, with $1.4 \%$ in the SAVR group and $1.8 \%$ in the ARE group. The authors concluded that ARE can be performed safely in experienced centres with no significant increase in the risk of early postoperative surgical complications and early mortality.

Sá et al. ${ }^{[30]}$ carried out a meta-analytical study to evaluate the impact of surgical ARE on the perioperative outcomes of SAVR with 10 studies published from 2002 to 2018 and a total of 13,174 patients (SAVR with ARE: 2,819 patients; SAVR without ARE: 10,355 patients). The total rate of ARE was $21.4 \%$, varying in the studies from $5.7 \%$ to $26.3 \%$. The OR for perioperative mortality showed a statistically significant difference between the groups, with a higher risk in the "SAVR with ARE" group (OR 1.506, 95\% CI 1.209$1.875, P<0.001)$ than in the "SAVR without ARE" group, but not when adjusted for isolated SAVR + ARE without any concomitant procedures, such as mitral valve surgery, coronary artery bypass surgery, etc. (OR 1.625, 95\% Cl 0.968-2.726, $P=0.066)$. The "SAVR with ARE" group showed an overall lower risk of significant PPM (OR 0.472, 95\% Cl 0.295-0.756, $P=0.002$ ) and a higher overall difference in means of iEOA than the "SAVR without ARE" group.

\section{Sutureless Valves as Another Option to Avoid Predicted PPM after TAVI}

Usual aortic valve prostheses narrow the EOA due to their suturing ring. Sutureless valve prostheses, on the other hand, are stentless and offer the advantage of a larger EOA, hence low rates of PPM. Beckmann et al. ${ }^{[31]}$ carried out a study with 128 patients to compare the perioperative and mid-term outcomes of patients undergoing surgery for aortic valve stenosis with a small annulus that received either conventional AVR with ARE (36 patients) or implantation of a sutureless valve (92 patients). Albeit comprised of older patients, the group that received sutureless 
Study name

$\begin{array}{lcccc} & \begin{array}{c}\text { Odds } \\ \text { ratio }\end{array} & \begin{array}{c}\text { Lower } \\ \text { limit }\end{array} & \begin{array}{c}\text { Upper } \\ \text { limit }\end{array} & \text { p-Value } \\ \text { León del Pino 2019 } & 1,597 & 0,400 & 6,368 & 0,507 \\ \text { VIVID Registry 2018 } & 0,771 & 0,462 & 1,288 & 0,320 \\ \text { STS/ACC TVT Registry 2018 } & 0,978 & 0,929 & 1,029 & 0,386 \\ \text { Schofer 2018 } & 1,110 & 0,798 & 1,545 & 0,535 \\ \text { OCEAN-TAVI Registry 2018 } & 1,386 & 0,784 & 2,449 & 0,262 \\ \text { Zbroñski 2017 } & 1,140 & 0,426 & 3,054 & 0,794 \\ \text { PARTNER II Nested Registry 2017 } & 0,580 & 0,306 & 1,100 & 0,095 \\ \text { PARTNER Trial 2014 } & 1,126 & 0,589 & 2,152 & 0,721 \\ \text { PARTNER NRCA Registry 2014 } & 0,949 & 0,695 & 1,297 & 0,744 \\ \text { Muñoz-García 2013 } & 1,304 & 0,335 & 5,068 & 0,702 \\ \text { Kukucka 2013 } & 1,217 & 0,590 & 2,510 & 0,595 \\ \text { Overall effect } & 0,980 & 0,933 & 1,029 & 0,423\end{array}$

Test for heterogeneity: $\mathrm{Chi}^{2}=6.70 ; \mathrm{df}=10(\mathrm{P}=0.754) ; \mathrm{I}^{2}=0.0 \%$

Test for overall random effect: $Z=-0.82(P=0.423)$
Odds ratio and $95 \% \mathrm{Cl}$

1-year Mortality

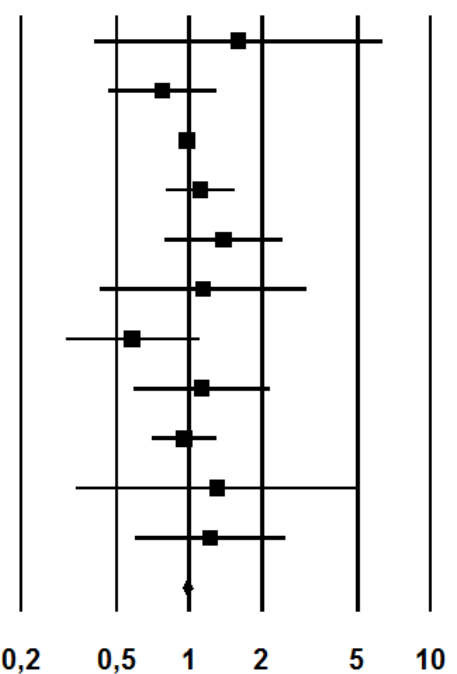

No PPM Moderate PPM

Fig. 3 - Odds ratio and conclusions plot of 1-year mortality for moderate prosthesis-patient mismatch (PPM). This figure shows the summary effect of no versus moderate PPM on 1-year mortality.

$\mathrm{Cl}=$ confidence interval

Study name

León del Pino 2019

VIVID Registry 2018

STS/ACC TVT Registry 2018

Schofer 2018

OCEAN-TAVI Registry 2018

Zbroñski 2017

PARTNER II Nested Registry 2017

CoreValve US High Risk Pivotal Trial 2016

NOTION Trial 2016

PARTNER Trial 2014

PARTNER NRCA Registry 2014

Muñoz-García 2013

Kukucka 2013

Overall effect
Statistics for each study

$\begin{array}{rrrr}\begin{array}{r}\text { Odds } \\ \text { ratio }\end{array} & \begin{array}{c}\text { Lower } \\ \text { limit }\end{array} & \begin{array}{c}\text { Upper } \\ \text { limit }\end{array} & \text { p-Value } \\ 3,667 & 0,676 & 19,876 & 0,132 \\ 0,818 & 0,463 & 1,445 & 0,489 \\ 1,098 & 1,028 & 1,173 & 0,005 \\ 1,219 & 0,814 & 1,826 & 0,336 \\ 0,492 & 0,029 & 8,404 & 0,624 \\ 1,108 & 0,127 & 9,693 & 0,926 \\ 0,855 & 0,323 & 2,264 & 0,752 \\ 1,818 & 0,587 & 5,629 & 0,300 \\ 0,829 & 0,041 & 16,747 & 0,902 \\ 0,438 & 0,173 & 1,105 & 0,080 \\ 1,267 & 0,860 & 1,867 & 0,232 \\ 15,400 & 3,965 & 59,810 & <0,001 \\ 2,714 & 1,006 & 7,325 & 0,049 \\ 1,109 & 1,041 & 1,181 & 0,001\end{array}$

Test for heterogeneity: $\mathrm{Chi}^{2}=26.56 ; \mathrm{df}=12(\mathrm{P}=0.009) ; \mathrm{I}^{2}=54.8 \%$

Test for overall random effect: $Z=3.21(P=0.001)$

Odds ratio and $95 \% \mathrm{Cl}$

1-year Mortality

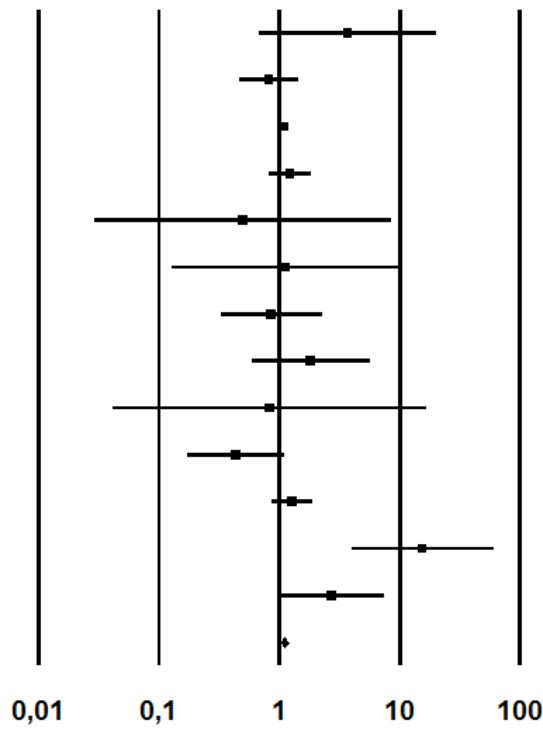

No PPM Severe PPM

Fig. 4 - Odds ratio and conclusions plot of 1-year mortality for severe prosthesis-patient mismatch (PPM). This figure shows the summary effect of no versus severe PPM on 1-year mortality.

$\mathrm{Cl}=$ confidence interval 
Funnel Plot of Standard Error by Log odds ratio
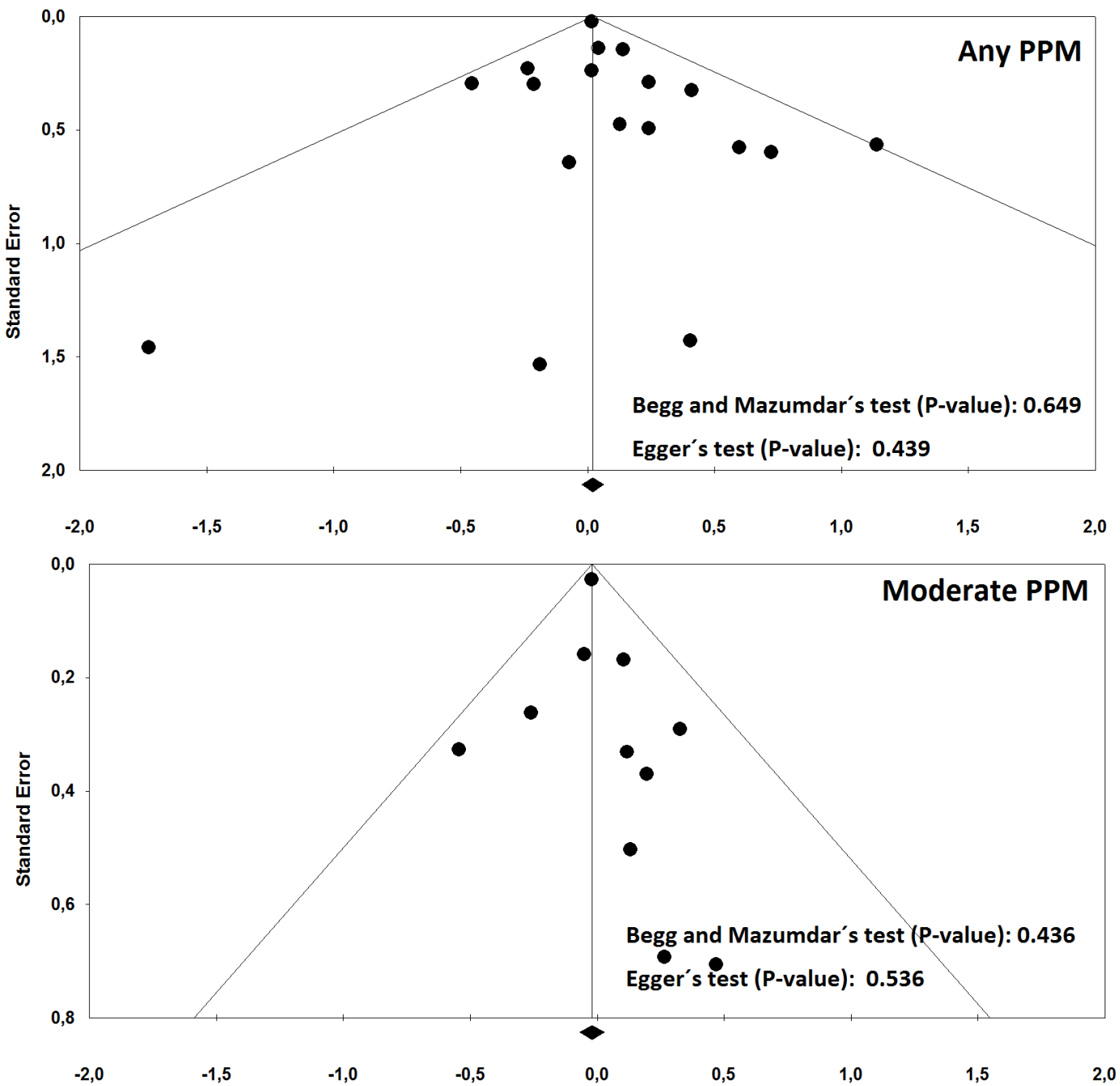

Log odds ratio

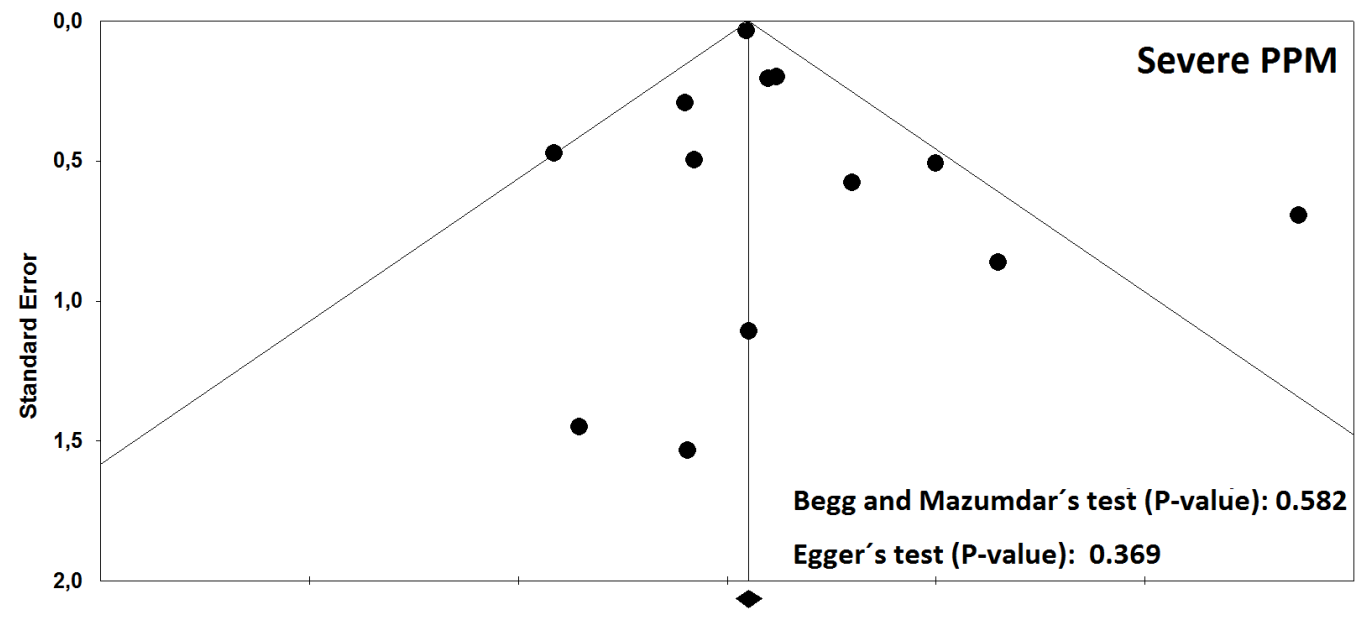

Fig. 5 - Publication bias. Funnel plot analysis of the outcomes. PPM=prosthesis-patient mismatch. 
valves had a 30-day mortality and survival rates comparable to those of the other group.

\section{Risk of Bias and Limitations}

There are inherent limitations with meta-analyses, including the use of cumulative data from summary estimates. Patient data were gathered from published data, not from individual patient follow-up. Access to individual patient data would have enabled us to conduct further subgroup analysis and propensity analysis to account for differences between the treatment groups. This meta-analysis included data from studies that reflect the "real world" but, on the other hand, are less limited by publication bias, treatment bias, confounders, and a certain tendency to overestimate treatment effects observed in the observational studies, since patient selection alters the outcome, and thus makes non-randomized studies less robust.

Moreover, considerable statistical heterogeneity was observed in one of the analyses, but we used the randomeffects model to counterbalance this aspect. We must remind the readers of the fact that research with statistically significant results is more likely to be submitted to medical journals and published than work with null or non-significant results, being the former also more likely to appear more prominently in English, in high-impact journals. All of the aforementioned aspects lead to the appearance of publication biases, but, in this case, we cannot state that the impact of severe PPM on mortality rates observed in our study is due to bias, since we observed low risk of bias in the analyses.

\section{CONCLUSION}

This meta-analysis found out that severe PPM is associated with a significant increase in 1-year mortality rates after TAVI.

\section{No financial support.}

No conflict of interest.

\section{REFERENCES}

1. Rahimtoola SH. The problem of valve prosthesis-patient mismatch. Circulation. 1978 Jul;58(1):20-4.

2. Pibarot P, Dumesnil JG. Hemodynamic and clinical impact of prosthesispatient mismatch in the aortic valve position and its prevention. J Am Coll Cardiol. 2000;36:1131-41.

3. Pibarot P, Clavel MA. Prosthesis-Patient Mismatch After Transcatheter Aortic Valve Replacement: It Is Neither Rare Nor Benign. J Am Coll Cardiol. 2018;72(22):2712-6. doi: 10.1016/j.jacc.2018.09.045.

4. Sá MPBO, Carvalho MMB, Sobral Filho DC, Cavalcanti LRP, Rayol SDC, Diniz RGS, Menezes AM, Clavel MA, Pibarot P, Lima RC. Surgical aortic valve replacement and patient-prosthesis mismatch: a meta-analysis of 108182 patients. Eur J Cardiothorac Surg. 2019 [Epub ahead of print]. doi: 10.1093/ejcts/ezy466.

5. Moher D, Liberati A, Tetzlaff J, Altman DG, for the PRISMA Group. Preferred reporting items for systematic reviews and metaanalyses: the PRISMA statement. Ann Intern Med. 2009;151:264-9.

\section{Authors' roles \& responsibilities}

MPBOS Substantial contributions to the conception or design of the work; or the acquisition, analysis, or interpretation of data for the work; drafting the work or revising it critically for important intellectual content; final approval of the version to be published.

LRPC Substantial contributions to the conception or design of the work; or the acquisition, analysis, or interpretation of data for the work; drafting the work or revising it critically for important intellectual content; final approval of the version to be published.

FASS Substantial contributions to the conception or design of the work; or the acquisition, analysis, or interpretation of data for the work; drafting the work or revising it critically for important intellectual content; final approval of the version to be published.

AMP Substantial contributions to the conception or design of the work; or the acquisition, analysis, or interpretation of data for the work; final approval of the version to be published.

SCR Substantial contributions to the conception or design of the work; or the acquisition, analysis, or interpretation of data for the work; drafting the work or revising it critically for important intellectual content; final approval of the version to be published.

RGSD Substantial contributions to the conception or design of the work; or the acquisition, analysis, or interpretation of data for the work; drafting the work or revising it critically for important intellectual content; final approval of the version to be published.

FBCAS Substantial contributions to the conception or design of the work; or the acquisition, analysis, or interpretation of data for the work; drafting the work or revising it critically for important intellectual content; final approval of the version to be published.

AMM Substantial contributions to the conception or design of the work; or the acquisition, analysis, or interpretation of data for the work; drafting the work or revising it critically for important intellectual content; final approval of the version to be published.

$\mathrm{RCL} \quad$ Final approval of the version to be published.

6. Higgins JP, Thompson SG, Deeks JJ, Altman DG. Measuring inconsistency in meta-analyses. BMJ. 2003;327:557-60.

7. DerSimonian R, Kacker R. Random-effects model for meta-analysis of clinical trials: an update. Contemp Clin Trials. 2007;28:105-14.

8. Begg CB, Mazumdar M. Operating characteristics of a rank correlation test for publication bias. Biometrics. 1994;50:1088-101.

9. Egger M, Davey Smith G, Schneider M, Minder C. Bias in metaanalysis detected by a simple, graphical test. BMJ. 1997;315:629-34.

10. Léon del Pino MC, Ruíz Ortiz M, Delgado Ortega M, Sánchez Fernández J, Ferreiro Quero C. Prosthesis-patient mismatch after transcatheter aortic valve replacement: prevalence and medium term prognostic impact. Int J Cardiovasc Imaging. 2019;35(01):1-206. doi: 10.1007/s10554-018-01519-z.

11. Lavagna F, Deharo P, Grisoli D, Gaubert G, Jaussaud N. Prosthesis patient mismatch is an independent predictor of congestive heart failure after transcatheter aortic valve replacement. Arch Cardiovasc Dis Suppl. 2019;11(01):65-6. doi:10.1016/j.acvdsp.2018.10.142.

12. Bleiziffer S, Erlebach M, Simonato M, Pibarot P, Webb J. Incidence, 
predictors and clinical outcomes of residual stenosis after aortic valvein-valve. Heart. 2018;104(10):828-34. doi:10.1136/heartjnl-2017-312422.

13. Herrmann H, Daneshvar S, Fonarow G, Stebbins A, Vemulapall S. Prosthesis-Patient Mismatch in 62,125 Patients Following Transcatheter Aortic Valve Replacement. J Am Coll Cardiol. 2018;72(22):2701-11. doi:10.1016/j.jacc.2018.09.001.

14. Seoudy H, Güßefeld N, Frank J, Freitag-wolf S, Lutter G. Incidence and impact of prosthesis-patient mismatch following transcatheter aortic valve implantation. Clin Res Cardiol. 2018;107(11):987-1086. doi:10.1007/ s00392-018-1394-0.

15. Schofer N, Deuschl F, Rübsamen N, Skibowski J, Seiffert M. ProsthesisPatient Mismatch after Transcatheter Aortic Valve Implantation: Prevalence and Prognostic Impact under Consideration of Baseline Left Ventricular Function. Eurolntervention. 2018;JAA(484). doi:10.4244/EIJ-D-18-00827.

16. Miyasaka M, Tada N, Taguri M, Kato S, Enta Y. Incidence, Predictors, and Clinical Impact of Prosthesis-Patient Mismatch Following Transcatheter Aortic Valve Replacement in Asian Patients: The OCEAN-TAVI Registry. JACC Cardiovasc Interv. 2018;11(08):771-80. doi:10.1016/j.jcin.2018.01.273.

17. Zbroński K, Rymuza B, Scisło P, Grodecki K, Dobkowska P. Patient-prosthesis mismatch in patients treated with transcatheter aortic valve implantation - predictors, incidence and impact on clinical efficacy A preliminary study. Advances in Interventional Cardiology. 2017;13(04 (50)):281-7. doi:10.5114/aic.2017.71608.

18. Mooney J, Sellers SL, Blanke P, Pibarot P, Hahn RT, et al. CT-Defined Prosthesis-Patient Mismatch Downgrades Frequency and Severity, and Demonstrates No Association With Adverse Outcomes After Transcatheter Aortic Valve Replacement. JACC Cardiovasc Interv. 2017;10(15):1578-87. doi:10.1016/j.jcin.2017.05.031.

19. Zorn GL 3rd, Little SH, Tadros P, Deeb GM, Gleason TG, Heiser J, Kleiman NS, Oh JK, Popma JJ, Adams D, Huang J, Reardon MJ. Prosthesispatient mismatch in high-risk patients with severe aortic stenosis: A randomized trial of a self-expanding prosthesis. J Thorac Cardiovasc Surg. 2016;151(4):1014-22. doi: 10.1016/j.jtcvs.2015.10.070.

20. Poulin F, Yingchoncharoen T, Wilson WM, Horlick EM, Généreux P. Impact of Prosthesis-Patient Mismatch on Left Ventricular Myocardial Mechanics After Transcatheter Aortic Valve Replacement. J Am Heart Assoc. 2016;05(02). doi:10.1161/JAHA.115.002866.

21. Thyregod HGH, Steinbrüchel DA, Ihlemannb N, Ngo TA, Nissen H. No clinical effect of prosthesis-patient mismatch after transcatheter versus surgical aortic valve replacement in intermediate- and low-risk patients with severe aortic valve stenosis at mid-term follow-up: an analysis of the NOTION trialt. Eur J Cardiothorac Surg. 2016;50(04):721-8. doi:10.1093/ ejcts/ezw095.

22. Pibarot P, Weissman NJ, Stewart WJ, Hahn RT, Lindman BR. Incidence and Sequelae of Prosthesis-Patient Mismatch in Transcatheter Versus Surgical Valve Replacement in High-Risk Patients With Severe Aortic Stenosis. J Am Coll Cardiol. 2014;64(13):1323-34. doi:10.1016/j.jacc.2014.06.1195.

23. Muñoz-García AJ, Muñoz-García M, Carrasco-Chinchilla F, et al. Incidence and clinical outcome of prosthesis-patient mismatch after transcatheter aortic valve implantation with the CoreValve prosthesis. Int J Cardiol. 2013;167:1074-6

24. Kukucka M, Pasic M, Dreysse S, et al. Patient-prosthesis mismatch after transapical aortic valve implantation: incidence and impact on survival. J Thorac Cardiovasc Surg. 2013;145:391-7.

25. Van Linden A, Kempfert J, Blumenstein J, et al. Prosthesis-patient mismatch after transcatheter aortic valve implantation using the Edwards SAPIEN prosthesis. Thorac Cardiovasc Surg. 2013;61:414-20.

26. Ewe SH, Muratori M, Delgado V, et al. Hemodynamic and clinical impact of prosthesis-patient mismatch after transcatheter aortic valve implantation. J Am Coll Cardiol. 2011;58:1910-8.

27. Dayan V, Vignolo G, Soca G, Paganini JJ, Brusich D, Pibarot P. Predictors and Outcomes of Prosthesis-Patient Mismatch After Aortic Valve Replacement. JACC Cardiovasc Imaging. 2016;9(8):924-33. doi: 10.1016/j. jcmg.2015.10.026.

28. Hahn RT, Leipsic J, Douglas PS, AberWA, Weissman NJ5, Pibarot P, Blanke P, Oh JK. Comprehensive Echocardiographic Assessment of Normal Transcatheter Valve Function. JACC Cardiovasc Imaging. 2019;12(1):2534. doi: 10.1016/j.jcmg.2018.04.010.

29. Haunschild J, Scharnowski S, Mende M, von Aspern K, Misfeld M, Mohr F-W et al. Aortic root enlargement to mitigate patient-prosthesis mismatch: do early adverse events justify reluctance? Eur J Cardiothorac Surg. 2019; doi:10.1093/ejcts/ezz016.

30. Sá MPBO, Carvalho MMB, Sobral Filho DC, Cavalcanti LRP, Diniz RGS, Rayol SC et al. Impact of surgical aortic root enlargement on the outcomes of aortic valve replacement: a meta-analysis of 13174 patients. Interact Cardiovasc Thorac Surg. 2019; doi:10.1093/icvts/ivy364.

31. Beckmann E, Martens A, Alhadi F, Hoeffler K, Umminger J, Kaufeld T et al. Aortic valve replacement with sutureless prosthesis: better than root enlargement to avoid patient-prosthesis mismatch? Interact Cardiovasc Thorac Surg. 2016;22:744-9. 